\title{
Iridoids from Vitex cymosa
}

\author{
Tereza C. dos Santos ${ }^{a}$, Jan Schripsema ${ }^{b}$, Franco D. Monache ${ }^{c}$ and Suzana G. Leitão ${ }^{{ }^{*}}$ \\ ${ }^{\mathrm{a}}$ Núcleo de Pesquisas de Produtos Naturais, Universidade Federal do Rio de Janeiro, Ilha do Fundão, \\ Centro de Ciências da Saude, Bloco H, 21941-590, Rio de Janeiro - RJ, Brazil \\ ${ }^{\mathrm{b}}$ Setor de Química de Produtos Naturais, Universidade Estadual do Norte Fluminense, \\ LCQUI/CCT, Av. Alberto Lamego, 2000, 28015-620, Campos - RJ, Brazil \\ ${ }^{\mathrm{C}}$ Centro Chimica dei Recettori, C. N. R., Università Cattolica S. Cuore, Largo Francesco Vito, 1, 00168, Rome - Italy \\ ${ }^{\mathrm{d} D e p a r t a m e n t o ~ d e ~ P r o d u t o s ~ N a t u r a i s ~ e ~ A l i m e n t o s, ~ F a c u l d a d e ~ d e ~ F a r m a ́ c i a, ~ U n i v e r s i d a d e ~ F e d e r a l ~ d o ~ R i o ~ d e ~ J a n e i r o, ~}$ \\ Ilha do Fundão, CCS, Bloco A , 21941-590, Rio de Janeiro - RJ, Brazil
}

Este trabalho descreve o isolamento e a identificação, a partir de folhas de Vitex cymosa, de um novo iridóide não glicosídico chamado tarumal, além dos já conhecidos viteóide II e agnusídio.

A new iridoid, named tarumal, as well as the known iridoids viteoid II and agnuside were isolated from the leaves of Vitex cymosa and identified by spectroscopic methods.

Keywords: Vitex cymosa, Verbenaceae, iridoids, rotundial, tarumal, viteoid II, agnuside, crescentin II

\section{Introduction}

Vitex species (Verbenaceae) are small trees or shrubs occurring in tropical and subtropical regions. Plants of this genus have been used for a great variety of medicinal purposes as well as an incense with insecticidal properties ${ }^{1}$. Vitex cymosa Bertero is a small tree widely distributed in the Central and Amazon regions of Brazil where it is popularly known as "Tarumã-do-Igapó" and "Tarumã-do-alagado"2.

In 1995, Watanabe ${ }^{3}$ et al. isolated the monoterpene dialdehyde rotundial (3) as a new natural mosquito repellent from $V$. rotundifolia. In other studies, derivatives of aucubin

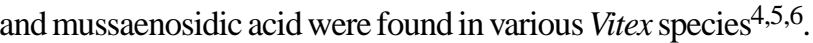

We now report the isolation and identification, from the leaves of $V$. cymosa, of a new iridoid, closely related to $\mathbf{3}$ which was named tarumal (1), as well as the known compounds viteoid II (2) and agnuside (4).

\section{Results and Discussion}

From the dichloromethane extract from the leaves of $V$. cymosa a new iridoid aglycone was isolated as a colourless oil which was named tarumal, (1).

*e-mail: sgleitao@pharma.ufrj.br

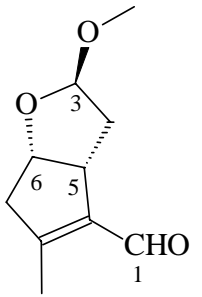<smiles>COC1(O)OC=CC2C(O)C=C(COC(=O)c3ccc(O)cc3)C21</smiles>

The ${ }^{1} \mathrm{H}$ NMR data of $\mathbf{1}$ showed some similarities with those of $\mathbf{3}$ (Table 1). In particular, the signals arising from the aldehyde conjugated with the endocyclic double bond at $\delta 9.98$ and the methyl group located on the same double bond at $\delta 2.17$. However, instead of the other aldehyde signal of 3 , a signal was observed at $\delta 5.00$, indicating the presence of an acetal. Further, a doublet of doublets at $\delta 4.65$ suggested the additional presence of an oxygen function and a three proton singlet at $\delta 3.33$ showed the presence of a methoxyl group. 


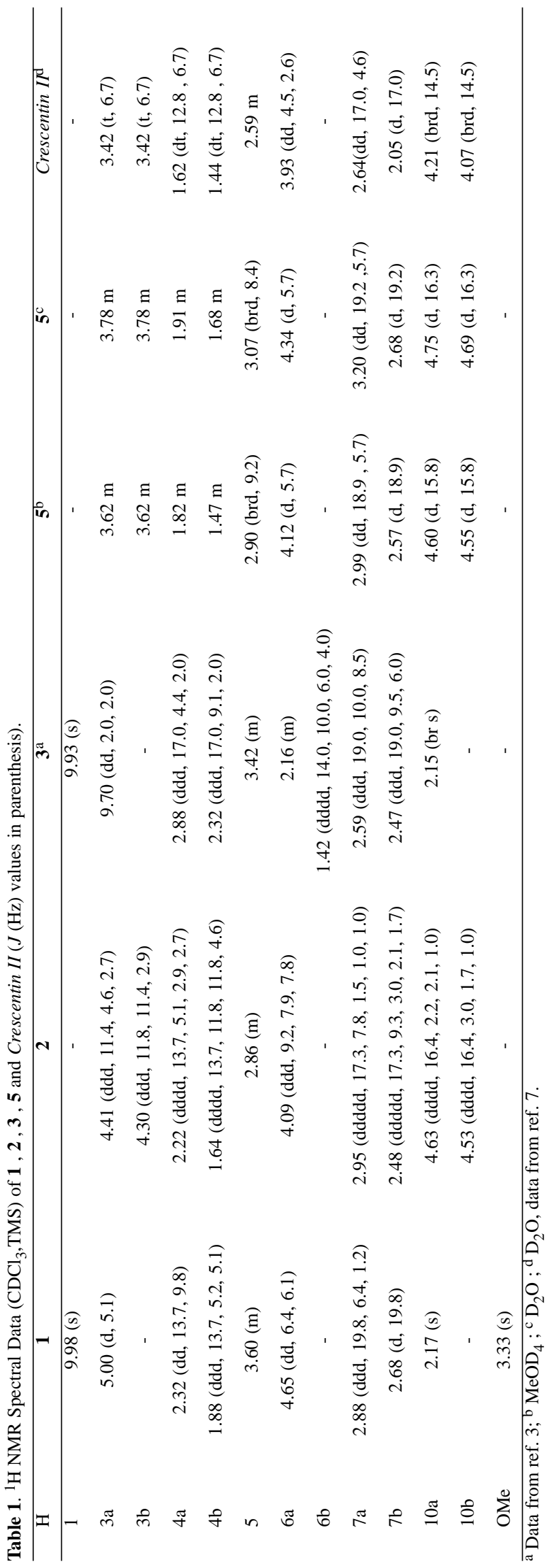

The ${ }^{13} \mathrm{C}$ NMR spectrum of $\mathbf{1}$ displayed 10 signals (Table 2). In comparison with the spectrum of $\mathbf{3}$ the replacement of the aldehyde by an acetal was confirmed by the absence of the signal at $\delta 201.9$ and the presence of an additional signal at $\delta 105.8$. Further, one methylene group was replaced by an oxygen bearing carbon $(\delta 78.4)$.

Table 2. ${ }^{13} \mathrm{C}$ NMR spectral data $\left(\mathrm{CDCl}_{3}, \mathrm{TMS}\right)$ of $\mathbf{1}, \mathbf{2}, \mathbf{3}, \mathbf{5}$ and Crescentin II.

\begin{tabular}{ccccccc}
\hline $\mathrm{C}$ & $\mathbf{1}$ & $\mathbf{2}$ & $\mathbf{3}^{\mathrm{a}}$ & $\mathbf{5}^{\mathrm{b}}$ & $\mathbf{5}^{\mathrm{c}}$ & Crescentin II $^{\mathrm{d}}$ \\
\hline 1 & 188.0 & 165.9 & 187.9 & 167.9 & 169.0 & 175.0 \\
3 & 105.8 & 70.8 & 201.9 & 61.5 & 61.4 & 59.5 \\
4 & 38.0 & 29.0 & 47.7 & 35.3 & 34.3 & 33.5 \\
5 & 47.3 & 51.0 & 38.0 & 54.4 & 53.7 & 52.2 \\
6 & 78.4 & 79.2 & 28.1 & 75.0 & 75.0 & 74.1 \\
7 & 46.0 & 42.2 & 39.0 & 43.9 & 43.9 & 45.3 \\
8 & 159.6 & 161.6 & 164.2 & 158.1 & 157.6 & 145.8 \\
9 & 139.6 & 123.6 & 139.0 & 130.9 & 130.6 & 133.5 \\
10 & 14.3 & 60.3 & 14.7 & 60.6 & 60.4 & 60.9 \\
OMe & 54.4 & - & - & - & - & \\
\hline a Data from ref. 3; ${ }^{\mathrm{b}} \mathrm{MeOD}_{4} ;{ }^{\mathrm{c}} \mathrm{D}_{2} \mathrm{O} ;{ }^{\mathrm{d}} \mathrm{D}_{2} \mathrm{O}$, data from ref. 7.
\end{tabular}

On the basis of these data the structure of $\mathbf{1}$ was obtained. The configuration at C-5 was considered to be R, (with a $5 \beta$-oriented $\mathrm{H}$ ) on biosynthetic grounds (its relation with $\mathbf{3}$, in which the same stereochemistry has been determined, see below). Furthermore, nearly all iridoids which have been found in nature have this configuration. Only a few exceptions are kown, none of which are within the family Verbenaceae. The ring closure with the substituent at C-6 requires the $\mathrm{S}$ configuration for the latter. By analysis of the coupling constants, the configuration of C-3 was determined to be $\mathrm{R}$ (Figure 1). This was confirmed by molecular modelling using the program Serena Software for PC, v. 4. 0 . This program uses a molecular mechanics approach to calculate the best conformation. In contrast to the programs using molecular orbital interactions the molecular mechanics approach can be used satisfactorily for the determination of configurations of 5-membered ring systems. For each of the C-3 configurations, two least energy conformations were found. One with the C-3 methoxyl-substituent in an axial position and another with the substituent in a equatorial position. Only 3R-tarumal with the methoxyl group in an axial position (Figure1) showed complete agreement of the calculated coupling constants with the experimental values. In this comparison all coupling constants of the complete molecule were considered. Especially the coupling constants of $\mathrm{H}-4 \alpha$ and $\mathrm{H}-4 \beta$ with both $\mathrm{H}-3$ and $\mathrm{H}-5$ showed large differences between the experimental and calculated coupling constants (see Table 3). According to the heats of formation calculated by PC-model for the conformers of 3R-tarumal, the conformer with the methoxyl group in an axial position should also be the most stable and thus be the predominant conformer. 


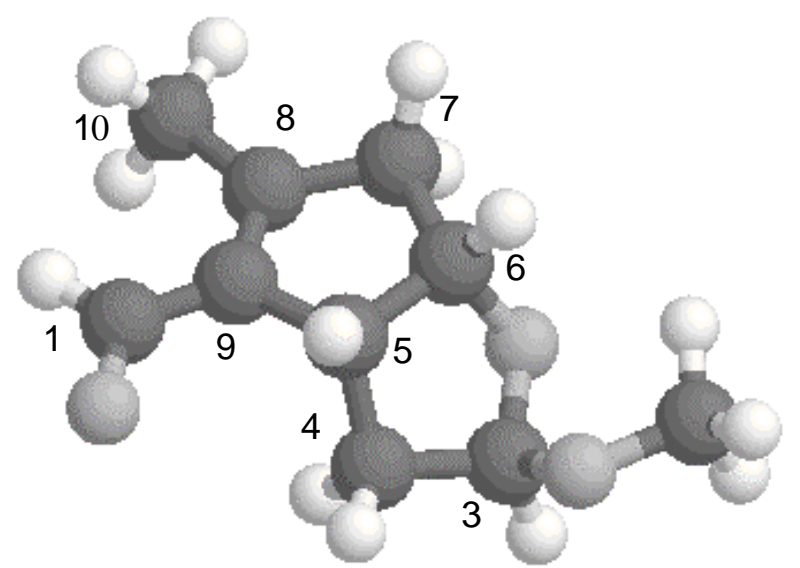

Figure 1. Stereochemical view of tarumal (1).

Table 3. Comparison of the experimental coupling constants $(J, \mathrm{~Hz})$ of tarumal (1) with those obtained from molecular modelling with the Serena Software for PC, v. 4.0. The calculated heats of formation ( $\mathrm{HF}, \mathrm{kcal} \mathrm{mol}^{-1}$ ) are also given. Data are given for both least energy conformations of $3 \mathrm{R}$ and $3 \mathrm{~S}$ tarumal. Eq and Ax refer to the equatorial or axial conformations of the 3-methoxyl group, respectively.

\begin{tabular}{lccccc}
\hline & Exp & 3R(ax) & 3R(eq) & 3S(ax) & 3S(eq) \\
\hline$J_{3-4 \alpha}$ & 0 & 1.4 & 8.7 & 5.5 & 6.4 \\
$J_{3-4 \alpha \beta}$ & 5.1 & 6.7 & 6.8 & 1.4 & 9.2 \\
$J_{5-4 \alpha}$ & 9.8 & 10.2 & 6.6 & 6.4 & 10.2 \\
$J_{5-4 \beta}$ & 5.2 & 6.0 & 1.0 & 1.1 & 6.0 \\
$\mathrm{HF}$ & & -105.8 & -104.6 & -103.6 & -101.4 \\
\hline
\end{tabular}

From the butanol extract of the leaves of the same plant, 1 was reisolated together with another iridoid aglycone which was identified as viteoid II (2). This extract also yielded the known iridoid agnuside (4), which has been isolated before from $V$. rotundifolia ${ }^{5} .{ }^{1} \mathrm{H}$ and ${ }^{13} \mathrm{C}$ NMR data reported in the literature for viteoid $\mathrm{H}^{5}$ are almost identical to those obtained for compound $\mathbf{2}$ (Tables 1 and 2). The relative stereo-chemistry proposed by the authors 5 is also in good agreement with our nOe difference experiments (Figure 2). Irradiation of H-6 yielded strong enhancements of the signals of $\mathrm{H}-7 \alpha(6.5$ $\%)$ and $\mathrm{H}-4 \beta$ (3. $2 \%$ ), while no enhancement of the $\mathrm{H}-5$ signal was observed. Irradiation of $\mathrm{H}-5$ yielded enhancements of $\mathrm{H}-4 \beta$ (3. $0 \%), \mathrm{H}-3 \beta(4.0 \%)$ and $\mathrm{H}-7 \beta$ $(6.1 \%)$. Based on the same arguments as mentioned above for $\mathbf{1}$, the configuration at C-5 should be R. Molecular modeling of $\mathbf{2}$ showed that the configuration at C- 6 should be $\mathrm{R}$. This was based on the comparison of the predicted values (data not shown) of all coupling constants of the entire molecule of both stereoisomers with the experimental values. The presence of a bicyclic structure was confirmed in the HMBC spectrum of $\mathbf{2}$ by a long range correlation of $\mathrm{C}-1$ ( $\delta 165.9)$ with $\mathrm{H}-3 \alpha$ and $\mathrm{H}-3 \beta$ at $\delta 4.41$ and $\delta 4.31$, respectively.

Upon standing in methanol, we observed that 2

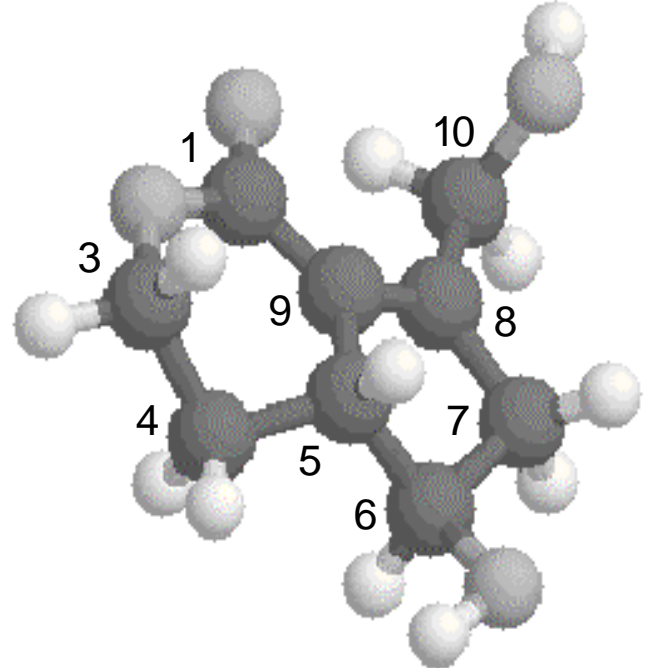

Figure 2. Stereochemical view of viteoid II (2).

decomposed to another product. This was also described for viteoid II $^{5}$ and the decomposition product was identified as 1-oxo-eucommiol (5). At the time of the submission of this paper, the same structure $\mathbf{5}$ was reported for another product, crescentin II, isolated from Crescentia cujete $^{7}$. Our present study confirms the structure published for 1oxo-eucommiol (5) and consequently the structure of crescentin II needs revision. However, we cannot suggest an alternative structure for crescentin II based on the published spectral data.

All the proton and carbon assignments of 1, 2 and 5 (Tables1 and 2) were confirmed by 2D NMR measurements (HSQC and HMBC).

In order to verify the possibility of $\mathbf{1}$ being an artifact, reisolation of this substance was performed without purification on Sephadex LH-20 using $\mathrm{MeOH}$. After fractionation of the dichloromethane extract by $\mathrm{CC}$ using a $\mathrm{CH}_{2} \mathrm{Cl}_{2}$-EtOAc gradient, the fractions eluted with $\mathrm{CH}_{2} \mathrm{Cl}_{2}$-EtOAC (9:1) which presumably contained 1 were analyzed by HPLC. The presence of 1 could be confirmed by comparison of retention times, UV spectra and coinjection with pure $\mathbf{1}$.

Compounds $\mathbf{1}$ and $\mathbf{2}$ are closely related to $\mathbf{3}$. Compound 1 might well be biosynthetically derived from 3 by a hydroxylation on C- 6 , subsequent hemiacetal formation with the $\mathrm{C}-3$ aldehyde, and a reaction with a molecule of $\mathrm{MeOH}$.

The occurrence of ciclopentene iridoids has been reported from various families. Recently the presence of rotundial was reported in Alberta magna 8 (Rubiaceae). The crescentins reported from Crescentia cujete (Bignoniaceae), borreriagenin from Borreria verticillata ${ }^{9}$ (Rubiaceae), the eucommiosides from Eucommia ulmoides ${ }^{4}$ (Eucommiaceae) 
and Aucuba japonica ${ }^{4}$ (Cornaceae) and the dolichodial derivative reported from Centranthus ruber ${ }^{10}$ (Labiatae) also show similar structures. The occurrence of these compounds does not seem to have much chemosystematic value.

\section{Experimental}

\section{General procedures}

${ }^{1} \mathrm{H}$ NMR (400 and $600 \mathrm{MHz}$ ) and ${ }^{13} \mathrm{C}$ NMR (100 and $150 \mathrm{MHz})$ : TMS as int. standard. Silica gel 60 (70-270 mesh, Merck) was used for CC and silica gel 60 F254 (Merck) plates for TLC. Substances were detected by UV light or by spraying $\mathrm{H}_{2} \mathrm{SO}_{4}$-EtOH (10:90). HPLC LaChrom, DAD detector (Merck-Hitashi).

\section{Plant material}

Vitex cymosa Bert. was collected in fruit at Corumbá, Mato Grosso do Sul, Brazil. It was identified by Dr. Vali Pott from EMBRAPA, Corumbá. A voucher specimen is deposited at Universidade Federal de Juiz de Fora Herbarium under the \# CESJ 11.711.

\section{Extraction and isolation}

Dried leaves $(2.2 \mathrm{~kg}$ ) were extracted with EtOH. After filtration and concentration under reduced pressure the aq. residue was sequentially extracted with $\mathrm{C}_{6} \mathrm{H}_{14}, \mathrm{CH}_{2} \mathrm{Cl}_{2}$, EtOAc and $n-\mathrm{BuOH}$. The dichloromethane extract $(10 \mathrm{~g})$ was chromatographed on silica gel eluted with $\mathrm{CH}_{2} \mathrm{Cl}_{2}$ with increasing amounts of EtOAc. Fractions $(100 \mathrm{mg})$ eluted with $\mathrm{CH}_{2} \mathrm{Cl}_{2}$ - EtOAc (9:1) were re-chromatographed on Sephadex LH-20 (MeOH), yielding 1 (10 mg). The butanolic extract (4g) was chromatographed on silica eluted with $\mathrm{CHCl}_{3}$ increasing amounts of $\mathrm{MeOH}$ yielding 120 fractions. Fracions 1-2, eluted with $\mathrm{CHCl}_{3}$, yielded $40 \mathrm{mg}$ of $\mathbf{1}$. Fractions 24-31, eluted with $\mathrm{CHCl}_{3}-\mathrm{MeOH}$ (8:2), were purified by silica gel preparative plates, eluted with EtOAc- $\mathrm{MeOH}$ (9:1) affording $20 \mathrm{mg}$ of 2. Fractions 35-52, eluted with $\mathrm{CHCl}_{3}-\mathrm{MeOH}$ (8:2), afforded, upon evaporation, $50 \mathrm{mg}$ of an amorphous solid which was identified as 4.

\section{HPLC for the detection of 1}

Fractions containing 1 obtained by silica gel $\mathrm{CC}$ of the $\mathrm{CH}_{2} \mathrm{Cl}_{2}$ extract eluted with $\mathrm{CH}_{2} \mathrm{Cl}_{2}$-EtOAc (9:1) were subjected to HPLC. Column: RP18 (250x 4 mm, $5 \mu$, Merck); mobile phase: $\mathrm{CH}_{3} \mathrm{CN}-\mathrm{H}_{2} \mathrm{O}$ (25-75); flow rate: $1 \mathrm{~mL} \mathrm{~min}^{-1}$.
Tarumal (1): Colourless oil, $[\alpha]_{\mathrm{D}}=+14.3(c, 1 \%$ in $\left.\mathrm{CHCl}_{3}\right) ;{ }^{1} \mathrm{H} \mathrm{NMR}\left(\mathrm{CDCl}_{3}\right)$ see Table 1 and ${ }^{13} \mathrm{C} \mathrm{NMR}$ $\left(\mathrm{CDCl}_{3}\right)$ see Table 2; EI-MS m/z $182[\mathrm{M}]^{+\cdot}(0 \%), 153$ [M$29]^{+}$(31.2), 152 [M-30] ${ }^{+}$(18.7), 79 (100).

Viteoid II (2): Colourless oil, $[\alpha]_{\mathrm{D}}=-62.7(c, 1 \%$ in $\mathrm{MeOH}) ;{ }^{1} \mathrm{H}$ NMR $\left(\mathrm{CD}_{3} \mathrm{OD}\right)$, see Table 1 and ${ }^{13} \mathrm{C}$ NMR $\left(\mathrm{CD}_{3} \mathrm{OD}\right)$, see Table 2; EI-MS m/z 198 [M] $^{+\cdot}(0 \%), 155$ $[\mathrm{M}-43]^{+}$(40.0), 109 [M-89] $^{+}$(43.0), 55 (100).

Agnuside (4): Amorphous solid, data according to Boros \&Stermitz ${ }^{4}$.

\section{Acknowledgments}

CAPES, CNPq, Brazil for fellowships (T.C.S and J.S) and the "Centro Nacional de Ressonância Magnética Nuclear”, Departamento de Bioquimica Médica, UFRJ, for access to the NMR facilities. This work was supported by PRONEX grant \# 41.96.0888.00. We thank Dr. Vali Pott for plant collection and identification and Dr. Mauro Barbosa Amorin, NPPN, UFRJ, for his advice regarding the molecular modelling.

\section{References}

1. Zhegan, C. ; Yurong, C. Chem. Abstr 1992, 116, 146177 y; Faming Zhuamli Shenqing Gongkai Shuomingshu CN 1, 053, 169 (CL.AO1N65/00), 24 Jul. 1991, Appl. 90, 105, 402, 06 Jan 1990; 7pp.

2. Corrêa, M. P. Dicionário das Plantas Úteis do Brasil e das Exóticas Cultivadas. 1926. Rio de Janeiro: Imprensa Nacional, IV, p.208.

3. Watanabe, K.; Takada, Y.; Matsuo, N.; Nishimura, H. Biosci. Biotech. Biochem. 1995, 59, 1979.

4. Boros, C. A.; Stermitz, F. R. J. Nat. Prod. 1990, $53,1055$.

5. Ono, M.; Ito, Y.; Kubo, S.; Nohara, T. Chem. Pharm. Bull. 1997, 45, 1094.

6. Suksamrarn, S.; Kumcharoen, S.; Suksamrarn, A. Planta Medica 1999, 65, 392.

7. Kaneko, T.; Ohtani, K.; Kasai, R.; Yamasaki, K.; Minh Duc, N. Phytochemistry 1997, 46, 907.

8. Drewes, S. E.; Horn, M. M.; Connolly, J. D.; Bredenkamp, B. Phytochemistry 1998, 47, 991.

9. Vieira, I. J. C.; Mathias, L.; Braz-Filho, R.; Schripsema, J. Org. Lett. 1999, 1, 1169.

10. Boros, C. A.; Stermitz, F. R. J. Nat. Prod. 1991, $54,1173$. 